\title{
The abnormal urodynamic findings as a predictor of complete response to treatment in patients with complicated nocturnal enuresis
}

\author{
Nooman H. Saeed*, Ziad M. Awwad** \\ * Department of Surgery, College of Medicine, University of Mosul; ** Special Surgery Department \\ (Urology), Jordan University Hospital, Amman, Jordan.
}

(Ann. Coll. Med. Mosul 2011; 37 (1 \& 2): 129-134).

Received: $24^{\text {th }}$ May 2010; Accepted: $26^{\text {th }}$ Oct. 2011.

\begin{abstract}
Objective: Patients with complicated nocturnal enuresis might show poor response to various forms of treatments, the purpose of this study is to urodynamically assess their bladder function and capacity aiming to predict the underlying cause for their problem and to assess their response to treatment with desmopressin and anticholinergics(oxybutynin).

Patients and methods: A retrospective study of 63 patients (50 female and 13 male). Their age ranged between 5-14 years, complaining of complicated nocturnal enuresis. Conducted at the urology clinic in Jordan University Hospital in Amman. All patients underwent urodynamic study, their data were analyzed, and treatment was established accordingly. Response was compared between patients having bladder instability and those with stable bladder, also between those with normal cystometric capacity and those with reduced cystometric capacity.

Results: Bladder instability was reported in 55 patients (87.3\%) as compared to 8 patients $(12.7 \%)$ with stable bladder. Also 52 patients $(82.5 \%)$ had reduced bladder capacity and 11 patients $(17.5 \%)$ had normal bladder capacity. Of 52 patients with reduced cystometric capacity, 42 patients $(80.7 \%)$ had partial or no response to treatment.

Conclusion: Management of patients with complicated nocturnal enuresis is challenging, and needs an elaborate efforts to settle the cause(s). Bladder instability and reduced bladder capacity represent significant part of the underlying etiologies. The reduced bladder capacity is a reliable predictor of response to treatment with desmopressin and anticholinergics in this group of patients.
\end{abstract}

Keywords: Complicated nocturnal enuresis, urodynamics.

الخلاصة

الههف: سلس البول المعقد هو التبول اللاإرادي أثناء النوم يصبحه أعراض أخرى عند فترة الاستيقاظ مثل التبول

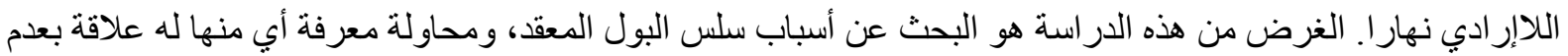
الاستجابة للعلاجات المقترحة.

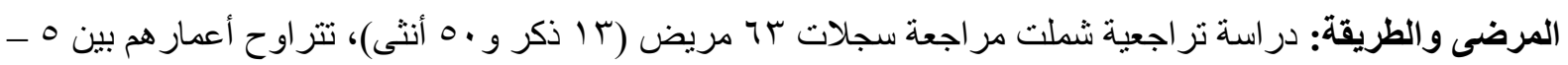

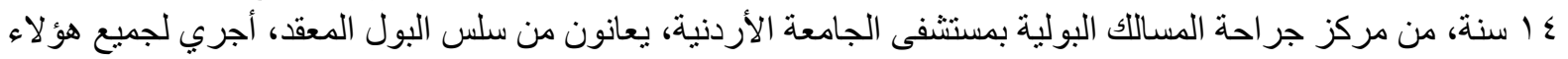

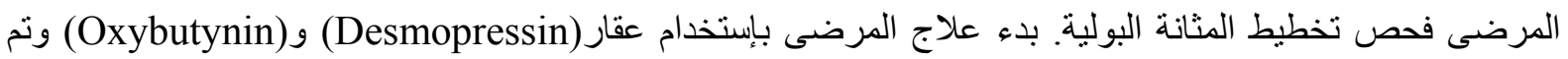
مقارنة استجابة المرضى اللعلاج.

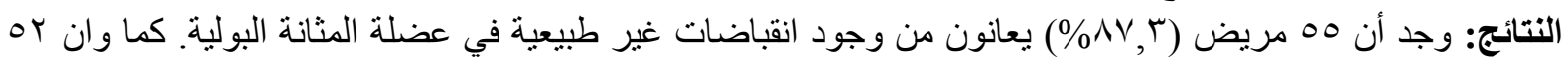

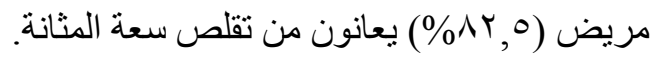




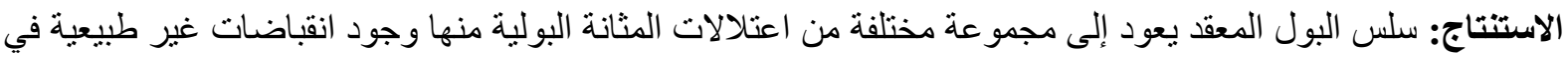

عضلة المثانة وتقلص سعة المثانة، وان تقلص سعة المثنانة البولية هو العامل الألهم في إمكانية توقع عدم الاستجابة الكية الكاملة

$\mathrm{N}$ octurnal enuresis is defined as; involuntary voiding that occurs during sleeping at night $^{(1)}$. Approximately $15 \%$ of children are still wetting their beds at night at 5 years of age and $1 \%$ at 15 years of age ${ }^{(1)}$. When it is not associated with day time symptoms it is called monosymptomatic or uncomplicated nocturnal enuresis, when day time symptoms such as frequency, urgency, incontinence, or chronic constipation are present it is called polysymptomatic or complicated nocturnal enuresis ${ }^{(1)}$. About $20 \%$ of nocturnal enuresis is of complicated type ${ }^{(1)}$. There is close relationship between complicated nocturnal enuresis and various types of bladder dysfunctions ${ }^{(2-6)}$. Some authors agreed that in neurologically normal enuretic children, with the absence of urinary tract abnormalities and urinary tract infections, complicated nocturnal enuresis is closely related to detrusor instability ${ }^{(7-10)}$.

The aim of this study is to evaluate bladder function and capacity in children with complicated nocturnal enuresis who are neurologically normal by using urodynamics, and to predict their response to treatment with desmopressin and anticholinergics (oxybutynin).

\section{Patients and methods}

A retrospective study that was conducted by reviewing the records of 63 patients who were referred to the urology clinic at Jordan University Hospital, complaining of complicated nocturnal enuresis, between January 2002-December 2006. The clinical and urodynamic records were reviewed including history and detailed enuretic diary, physical examination, investigations including urine analysis, culture and sensitivity, renal function test, urinary tract ultrasound, IVU, and MCUG confirming the absence of urinary tract abnormalities. Those children who were found to have urinary tract infection were treated with antibiotics before performing the urodynamic study to avoid the effect of urinary tract infection on urodynamic results.

Urodynamic study was performed as an out patient procedure using Duet computerized urodynamic system, conventional fill cystometric study was used. All urodynamic study records were analyzed, and bladder function assessed with respect to detrusor activity during filling phase, pattern of contractions, bladder capacity, presence of leak during filling phase, and presence of post void residue. Detrusor over activity was defined as abnormal detrusor contractions with pressure that exceeded $10 \mathrm{~cm} \mathrm{H}_{2} \mathrm{O}$ that the patient could not suppress them during filling phase $^{(11)}$. Bladder capacity referred to the maximum cystometric capacity achieved where the patient could not afford any more due to severe urgency, pain, or when urine leak has started ${ }^{(1)}$. Bladder capacity was considered reduced if it is less than the predicted capacity for age calculated by using Koffs formula ${ }^{(8)}(($ age +2$) \times 30)$. Patients were started on desmopressin $0.2 \mathrm{mg}$ tablet once per day at bed time and anticholinergics (oxybutynin $0.2 \mathrm{mg} / \mathrm{kg} /$ dose t.i.d.). The patients were followed up monthly to start with, then the intervals increased up to every three months according to patients responses. Follow up period ranged from 12-60 months (mean 21 months), and it included urinary diary, repeating urodynamic study to evaluate patients response to treatment. The patients were observed to have three types of response:

I- No response: including those who did not show any clinical response to treatment.

II- Partial or incomplete response: including those who showed improvement of nocturnal enuresis and/or improvement of day time symptoms but did not become totally asymptomatic. 
III- Complete response: including those who became totally dry at night and asymptomatic at day time.

In those who became totally asymptomatic gradual termination of the drugs was performed over few months, while those with incomplete or no response to treatment more prolonged therapy was attempted together with frequent repetition of urodynamics and more sophisticated studies and therapy regimens.

\section{Results}

The study included 63 patients (50 female $(79.4 \%)$ and 13 male (20.6\%)). Their age ranged between 5-14 years with mean age of 8.87 years (age was recorded at time of first consultation), there was no significant difference in age between male and female patients. At urodynamic study evaluation the patients were classified into those who had stable bladder (8 patients) and those with bladder instability (55 patients)(Figure1). Also patients were grouped into those who had normal cystometric capacity (11 patients) and those with reduced cystometric capacity (52 patients)(Figure 2). The overall response rate was shown in table 1. Regarding response rate in relation to bladder stability (table 2 ), those patients who had stable bladder showed complete response in 4 patients (50\%), and partial response in 4 patients (50\%). Whereas those with bladder instability had complete response in 16 patients (29\%), partial response in 32 patients (58\%), and no response in 7 patients (13\%). There was no statistically significant correlation between bladder instability and response rate $(P=0.35)$. On evaluation of bladder capacity and response rate (table 3 ), the patients who had normal bladder capacity showed complete response in 10 of them (90.9\%), and partial response in 1 patient only (9.1\%). As compared to patients who had reduced cystometric capacity where response rate was complete in 10 patients (19.2\%), partial in 35 patients (67.3\%) and no response in 7 patients $(13.5 \%)$. So of the 52 patients $(82.5 \%)$ who had reduced cystometric capacity, 42 patients $(80.7 \%)$ had partial or no response to treatment, which was statistically significant $(P=0.001)$.

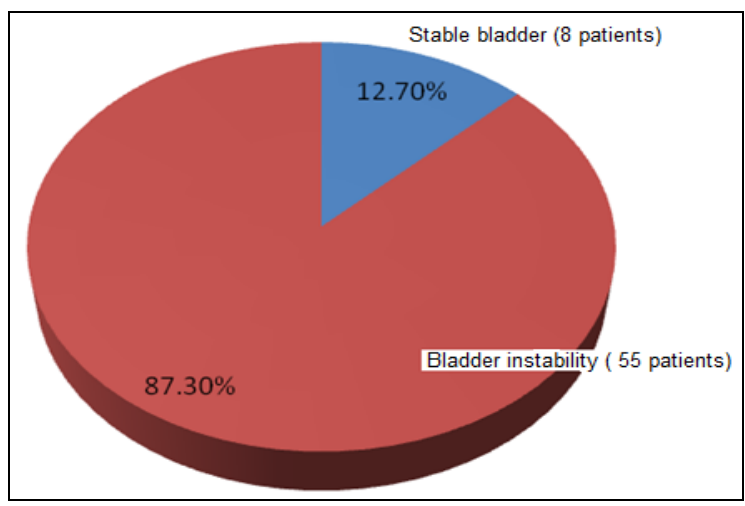

Figure (1): Bladder stability.

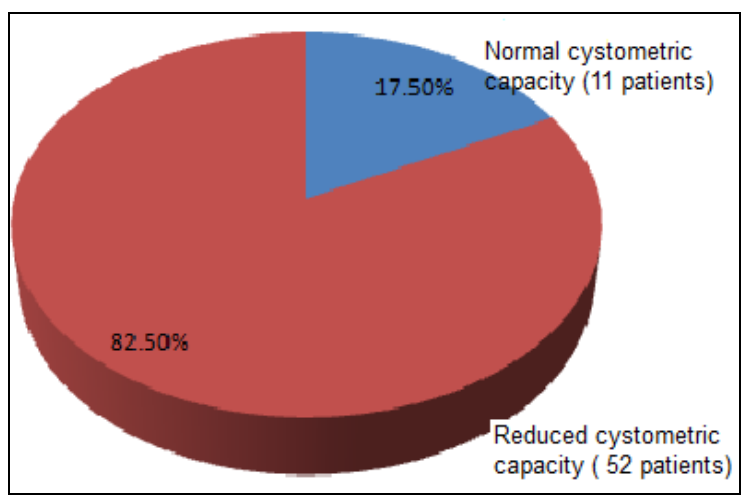

Figure (2): Bladder capacity.

Table (1): Overall response in all patients.

\begin{tabular}{|l|c|c|}
\hline Complete & 20 patients & $(31.7 \%)$ \\
\hline Partial & 36 patients & $(57.1 \%)$ \\
\hline No response & 7 patients & $(11.1 \%)$ \\
\hline
\end{tabular}

Table (2): Response rate in relation to bladder stability.

\begin{tabular}{|l|c|c|c|}
\hline Patients & $\begin{array}{c}\text { No } \\
\text { Response } \\
(\%)\end{array}$ & $\begin{array}{c}\text { Partial } \\
\text { Response } \\
(\%)\end{array}$ & $\begin{array}{c}\text { Complete } \\
\text { Response } \\
(\%)\end{array}$ \\
\hline Total & $7(11.1 \%)$ & $36(57.1 \%)$ & $20(31.7 \%)$ \\
\hline Stable & $0(0 \%)$ & $4(6.3 \%)$ & $4(6.3 \%)$ \\
\hline Instable & $7(11.1 \%)$ & $32(50.8 \%)$ & $16(25.4 \%)$ \\
\hline
\end{tabular}


Table (3): Response rate in relation to bladder capacity.

\begin{tabular}{|l|c|c|c|}
\hline Patients & $\begin{array}{c}\text { No } \\
\text { Response } \\
(\%)\end{array}$ & $\begin{array}{c}\text { Partial } \\
\text { Response } \\
(\%)\end{array}$ & $\begin{array}{c}\text { Complete } \\
\text { Response } \\
(\%)\end{array}$ \\
\hline Total & $7(11.1 \%)$ & $36(57.1 \%)$ & $20(31.7 \%)$ \\
\hline $\begin{array}{l}\text { Normal } \\
\text { capacity }\end{array}$ & $0(0 \%)$ & $1(1.6 \%)$ & $10(15.9 \%)$ \\
\hline $\begin{array}{l}\text { Reduced } \\
\text { capacity }\end{array}$ & $7(11.1 \%)$ & $35(55.6 \%)$ & $10(15.9 \%)$ \\
\hline
\end{tabular}

\section{Discussion}

Nocturnal enuresis is a common problem that can affect healthy children ${ }^{(1)}$. It causes multiple psychological problems being a social stigma. Despite extensive research and advances in urology, still there is a significant controversy regarding its etiology and pathophysiology, and now it is generally accepted that multiple pathologic factors are probably involved ${ }^{(1)}$.

In this study bladder instability was found in $87.3 \%$ of the patients, this result was higher than what was found by Medel et al. where bladder instability was found in $79 \%$ of their patients ${ }^{(11)}$, and this is expected in cases of complicated nocturnal enuresis where bladder dysfunctions are predicted in quite large percentage of them, and it is higher than what is found in monosymptomatic nocturnal enuresis, where bladder dysfunctions in general are expected in around (49\%) of cases $^{(11)}$.

Also $82.5 \%$ of the patients were found to have lower bladder capacity than what is predicted for their age. Yeung et al studied preselected children with refractory monosymptomatic nocturnal enuresis, all of their patients were found to have low functional bladder capacity, and the majority had no nocturnal polyuria ${ }^{(2)}$. The theory that small functional bladder capacity can be a cause of nocturnal enuresis is not new, although published studies may have contradictory evidences, where some studies showed children with nocturnal enuresis have small functional bladder capacity, while others found it to be entirely normal ${ }^{(3-6)}$. Furthermore, some of previous studies included relatively few patients, and although there might have been a trend for smaller bladder capacity the differences might have not reached statistical significance ${ }^{(12,13)}$.

It is not clear whether the abnormal bladder contractions resulting in low bladder capacity. Interestingly Medel et al found children with larger than normal bladder capacity had a similar incidence of detrusor instability whether they had monosymptomatic or complicated nocturnal enuresis ${ }^{(11)}$.

Bladder instability was not significantly correlated with response to treatment and therefore could not predict the possibility of symptoms control. It was the reduced bladder capacity that showed significant correlation with poor response to treatment and predicted well the possibility of symptoms control. This finding is comparable with what was found in previous studies, but only desmopressin was used in monosymptomatic nocturnal enuresis ${ }^{(14)}$.

Treatment of complicated nocturnal enuresis needs to target the underlying pathology(s). Partial response to treatment was encountered in $57.1 \%$ of the included patients, some of those patients became totally free of symptoms at day time but still they had nocturnal enuresis, it seems that those patients have some of their underlying ongoing multipathologies responded to treatment while others not. Yeung et al studied children with refractory nocturnal enuresis, they found them to have various patterns of bladder dysfunctions, andclassified those patients into two main groups, including those with functional bladder capacity that only become reduced with the appearance of detrusor instability during sleep, and those with reduced functional bladder capacity at day and night ${ }^{(15)}$. It might be that those patients in the first group may explain why some patient with partial response to treatment became asymptomatic at daytime while continued to have nocturnal enuresis, and these differences in response to treatment again prove the multiple underlying pathologies for complicated nocturnal enuresis. Monitoring of those children at night by using continuous ambulatory urodynamics probably will cast further light on more hidden 
underlying pathologies. Cystometric monitoring during sleep in those patients revealed that sleeping disturbances and bladder dysfunction are common ${ }^{(16-21)}$. Nocturnal polyuria resulting from deranged circadian rhythm of ADH secretion occurs in around $70 \%$ of enuretic children in general ${ }^{(16-18)}$. Interestingly most of those enuretic children with refractory symptoms do not have abnormal diurnal/ nocturnal rhythm of $\mathrm{ADH}$ secretion and no significant nocturnal polyuria ${ }^{(18-20)}$. Whether it is an increased urine production or a reduced bladder capacity that results in the mismatch between nocturnal bladder capacity and the amount of urine produced during sleep at night, there must be a simultaneous arousal failure in response to bladder fullness before bedwetting occurs $^{(1)}$. These findings cast further interest on looking for more specific theories tailored to target the underling etiologies in dealing with refractory complicated nocturnal enuresis.

\section{Conclusion}

Complicated nocturnal enuresis belongs to a heterogeneous group of underlying etiologies. It is important to say; those patients are not only complaining of social problems but also they have disorders which need appropriate management to control their symptoms. Bladder instability and reduced cystometric capacity are significant offending findings. The bladder capacity is a reliable predictor of response to treatment with desmopressin and anticholinergics.

\section{References}

1. Yeung CK, Jennifer DY. Campbell-Walsh Urology. $9^{\text {th }}$ ed. Philadelphia: Saunders, 2007:3621 - 25.

2. Yeung CK, Chiu HN, Sit FK. Bladder dysfunction in children with refractory monosymptomatic primary nocturnal enuresis. J Urol. 1999; 169: 1049-1055.

3. Starfield B. Functional bladder capacity in enuretic and non-enuretic children. J Pediatr. 1967; 70: 77-81.

4. Jarvelin MR, Huttunen NP, Seppanen J, Seppanen $U$, Moilanen I. Screening of urinary tract abnormalities among day and night wetting children. Scand J. Urol. Nephrol. 1990; 24: 181-9.

5. Rushton HG, Belman $A B$, Zaontz MR, Skoog SJ. Sihelink S. The influence of small functional bladder capacity and other predictors on the response to desmopressin in the management of monosymptomatic nocturnal enuresis. J Urol. 1996; 156:651-5.

6. Eller DA, Austin PF, Tanguay S, Homsy YL. Daytime functional bladder capacity as a predictor of response to desmopressin in monosymptomatic nocturnal enuresis. Eur Urol. 1998; 33: 25-9.

7. Kondo A, Otani T, Takita T, Mitsuya H. Children with unstable bladder: clinical and urodynamic observation. J Urol 1983; 129: 88-91.

8. Koff SA. Evaluation and management of voiding disorders in children. Urol Clin North American. 1988; 4: 169-75.

9. Mayo ME, Burns MW. Urodynamic studies in children who wet. Br J Urol. 1990; 65: 641-5.

10. Moore KH, Richmond DH, Parys BT. Sex distribution of adult idiopathic detrusor instability in relation to childhood bedwetting. Br J Urol. 1991; 68: 479-82.

11. Medel R, Ruarte AC, Castera R, podesta ML. Primary enuresis: a urodynamic evaluation. Br J Urol. 1998;81: 50-52.

12. Norgaard JP. Urodynamics in enuresis \& reservoir function. Neurourol Urodyn. 1989; 8: 199-211.

13. Wille S. Functional bladder capacity and calcium-creatinine quota in enuretic patients, former enuretic and non enuretic controls. Scand J Urol Nephro. 1994; 28 : 353-7.

14. Hamano $\mathrm{S}$, Yamanishi $\mathrm{T}$, Igurachi $\mathrm{T}$, Ito $\mathrm{H}$, Murkami S. Functional bladder capacity as a predictor of response to desmopressin and retention control training in monosymptomatic nocturnal enuresis. Eur Uro. 2000; 37: 718-22.

15. Yeung CK, Sit FK, To LK, Chiu HN, Sihoe $J D$, Lee E, Wong C. Reduction in nocturnal functional bladder capacity is a common factor in the pathogenesis of 
refractory nocturnal enuresis. $\mathrm{Br} \mathrm{J}$ Urol. 2002; 90: 302-307.

16. Ritting S, Knudsen UB, Sorensen S, Djurhuus JC, Norgard JP. Abnormal diurnal rhythm of plasma vasopressin and urinary output in patients with enuresis. Am J physiology 1989; 56: 664-71.

17. Norguard JP, Pedersen EB, Djurhuus JC. Diurnal antidiuretic hormone levels in enuretics. J Urol. 1985; 134: 1029-31.

18. Ritting S, Knudsen UB, Sorensen S, Djurhuus JC. Norgaard JP. Desmopressin in nocturnal enuresis. Horus medical publications. 1989: 43-55.
19. Yeung CK, Chiu. HN, Sit FK. Sleep disturbance and bladder dysfunction in enuretic children with treatment failure: fact or fiction?. Scand J Urol nephol. 1999; 33: 20-23.

20. Moffatt ME, Harlos S, Kirshen, AJ, Burd L. Desmopressin acetate and nocturnal enuresis: How much do we know?. J Pediatrics1993; 92: 420-23.

21. Mark SD, Frank JD. Nocturnal Enuresis. Br J Urol. 1995; 75: 427-34. 